\title{
Latitudinal changes of copepod egg production rates in Atlantic waters: temperature and food availability as the main driving factors
}

\author{
Albert Calbet ${ }^{1, *}$, Susana Agustí ${ }^{2}$ \\ 'Department of Oceanography, University of Hawaii at Manoa, 1000 Pope Road, Honolulu, Hawaii 96822, USA \\ ${ }^{2}$ Instituto Mediterraneo de Estudios Avanzados (CSIC-UIB), c/ Miquel Marqués 21, E-07190 Esporles, Mallorca
}

(Islas Baleares), Spain

\begin{abstract}
Planktonic copepod abundance and egg production rates were determined in relation to temperature and chlorophyll concentration across a latitudinal transect in the Atlantic Ocean, ranging from $52^{\circ} \mathrm{S}$ to $24^{\circ} \mathrm{N}$. Copepod distribution followed a pattern similar to that of chlorophyll $a$, with higher values at the southern latitudes. In contrast, egg production rates were significantly higher in the Atlantic intertropical zone, in the vicinity of the Equator. Copepod abundance was determined mainly by phytoplankton concentration, while rate processes (egg production rates) depended on chlorophyll a concentration and temperature. We propose multiple regression models including these 2 factors that explain up to $70 \%$ of the carbon specific egg production rates. The accuracy of these models versus previous ones including only temperature is also discussed.
\end{abstract}

KEY WORDS: Atlantic Ocean · Copepod - Egg production · Chlorophyll · Temperature

\section{INTRODUCTION}

It is clear from laboratory studies that egg production rate increases with both food concentration and temperature up to a limit fixed by the physiological characteristics of each species (Corkett \& McLaren 1969, Iwasaki et al. 1977, Zurlini et al. 1978, Vidal 1980, Uye 1981, Calbet \& Alcaraz 1996, Saiz et al. 1997). However, their relative importance in regulating copepod production in marine ecosystems is still uncertain. Field measurements have shown that either food (Harris \& Paffenhöfer 1976, Huntley \& Boyd 1984, Kimmerer \& McKinnon 1987, Peterson et al. 1991, Davis \& Alatalo 1992, Saiz et al. 1997 amongst others) or temperature (McLaren 1963, Conover \& Huntley 1980, Uye 1981) can be responsible for limiting copepod growth or egg production. However, some authors (Huntley \& Lopez 1992, Hirst \& Sheader 1997) consider temperature as the main environmental factor controlling the growth rates of marine copepods, and they

•E-mail: acalbet@iniki.soest.hawaii.edu have presented temperature-dependent models estimating secondary production according to this factor alone (in the model of Hirst \& Sheader [1997], body size was also considered in the calculations). A key assumption in these models is the non-limiting nature of food availability for copepods in marine systems, with evidence to the contrary being seen as an inability to sample the relevant resources at appropriate temporal or spatial scales (Huntley \& Lopez 1992).

Part of the problem with previous analyses could be the bias of a data set lacking adequate information for tropical and subtropical ecosystems, where food is often low while temperature is high. These warm and oligotrophic areas represent a considerable portion of the oceans, but data from these areas concerning secondary production is scarce (Greze 1978, Conover 1979, Kimmerer 1984, Webber \& Roff 1995, Hopcroft et al. 1998a), probably as a consequence of the low biomass and high diversity of their copepod communities. Also, most of the studies of copepod growth or production are conducted in relatively small areas using different methods, which makes comparisons between zones subject to elevated noise. Hence, the collection 
of comparable data sets including a wide spectrum of locations (oceanic range) is of major importance for the understanding of the mechanisms involved in the control of secondary production on a broad scale.

This paper presents data on the abundance and egg production rates (EPR) of dominant copepod species along a transect in the Atlantic Ocean from $52^{\circ} \mathrm{S}$ to $24^{\circ} \mathrm{N}$. A major objective of the study was to determine the relative importance of temperature and food availability on copepod production, covering a wide range of environmental conditions in which the possible combinations of trophic status and temperature are distributed according to latitudinal gradients.

\section{METHODS}

Area surveyed. The study took place on board the RV BIO 'Hespérides' during March and April 1995 in the Atlantic Ocean (Fig. 1). The cruise track included sampling in the Patagonia platform (coast of Argentina) and the South Atlantic temperate area (PP\&SAT), the western portion of the South Atlantic subtropical gyre (SASG), the intertropical area around the equator (IE) and the southern extreme of the North Atlantic subtropical gyre (NASG).

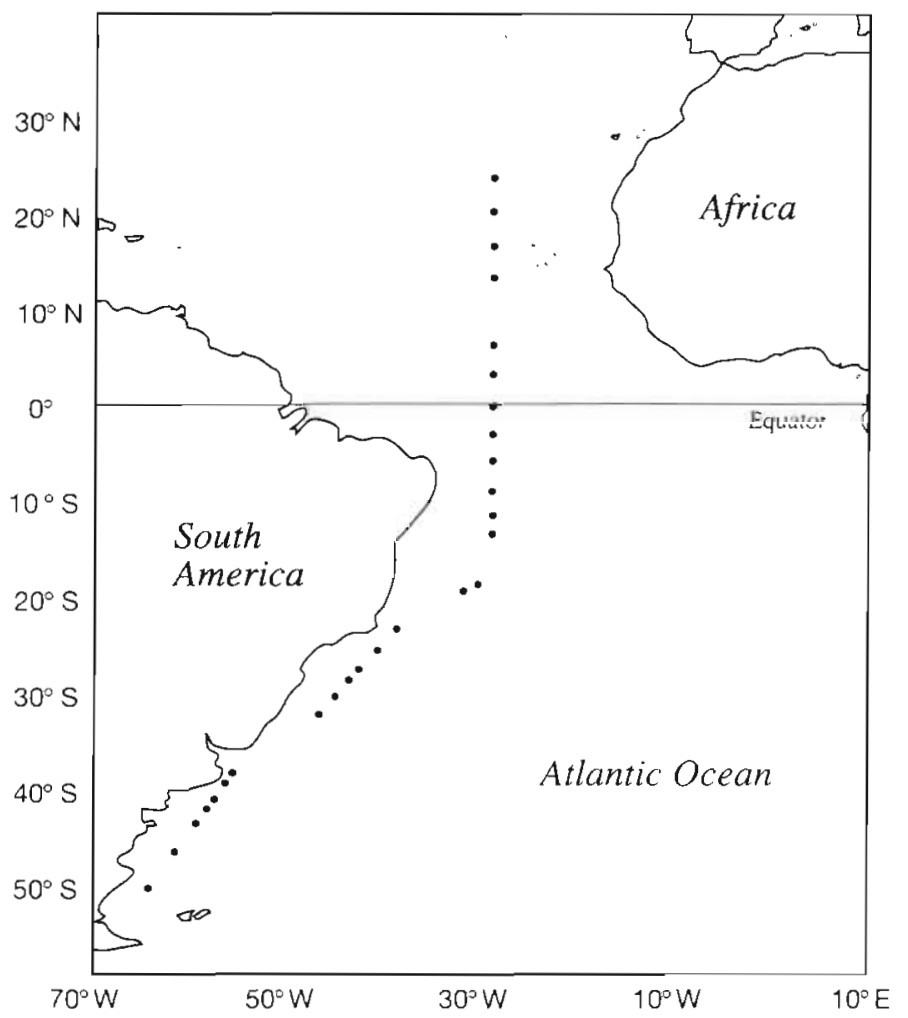

Fig. 1. Map of the study area with positions of the transect stations
Sampling strategy and production experiments. The hydrographic characteristics of the surveyed stations and fluorescence profiles were determined by CTD casts made with a Neil-Brown MARK-V CTD equipped with a Sea Tech fluorometer. Water samples from 6 to 8 depths were collected by 121 Niskin bottles installed in a rosette.

Chlorophyll a (chl a) concentrations were measured spectrophotometrically on acetone extracts. 3 to 51 of water was filtered onto $25 \mathrm{~mm}$ Whatman GF/F filters, homogenized and extracted in $90 \%$ acetone for $24 \mathrm{~h}$ and refrigerated in the dark. After pigment extraction, samples were read in an UV-Uvikon spectrophotometer using low volume $5 \mathrm{~cm}$ cuvettes, following Parsons et al. (1984).

The abundance of copepods was assessed during daylight by vertical tows made at $30 \mathrm{~m} \mathrm{~min}^{-1}$ with a WP-2 net fitted with $200 \mu \mathrm{m}$ mesh from $250 \mathrm{~m}$ depth (when possible) to the surface. Samples were preserved in buffered formalin ( $4 \%$ final concentration) for later study. Once in the laboratory, the composition of the copepod community (to genus level) was estimated by counting and identifying at least 250 individuals per sample.

Organisms were collected for experiments on egg production by means of vertical tows from 80 to $100 \mathrm{~m}$ to the surface at low speed $\left(10 \mathrm{~m} \mathrm{~min}^{-1}\right)$ using a $4 \mathrm{l}$ plastic bag as a non-filtering cod end. Once on deck, the samples were gently poured into an isothermic carboy and taken to the laboratory for the sorting of female copepods of the most abundant species under a stereomicroscope. From 1 to 10 individuals (depending on the size of the animals) were added to $600 \mathrm{ml}$ glass bottles filled with water from chlorophyll maximum. For most of the species, 5 to 6 copepods were incubated per bottle; however, for the smallest genera like Oithona or Macrosetella, a larger number of copepods $(\sim 10)$ were used. In the case of large copepods, like Calanus or Euchaeta, incubations were performed with a single female per bottle. Each experiment was replicated 5 to 7 times. Only undamaged adult females were chosen for the experiments. For egg-sac carrying species, only females without sacs at the time of the sorting were chosen. This procedure may have caused a bias when neglecting the production of females already carrying egg sacs. However, as most of the studied copepod species were sac spawners, the use of identical experimental criteria for all the stations allowed the comparison of the results across the latitudinal transect. In addition, among sac spawners, the proportion of females carrying egg sacs was very low at all the stations.

Incubations were performed in a temperature controlled room at the average temperature for the mixed layer. The light-dark cycle in the room was adjusted to 
ambient conditions at the sampling station. Bottles were gently turned upside-down at least twice during the incubation in order to minimize the settling of algae. After $24 \mathrm{~h}$ the contents of the incubation bottles were filtered through a submerged $20 \mu \mathrm{m}$ mesh sieve, the condition of the animals checked, and eggs and copepods preserved for further counting and sizing in the laboratory. In the case of sac spawners, eggs within free sacs and those attached to the female were counted. Empty shells were also counted and included in the calculations of egg production rates. Copepods were measured with an image analysis system consisting of a black and white video camera installed on an Olympus stereomicroscope connected to a Power Macintosh computer. The software utilized (NIH Image for Macintosh) allowed easy sizing of the animals. Conversions from copepod size to carbon content were made according to the equations of Uye (1982), Chisholm \& Roff (1990), or Webber \& Roff (1995) depending on the species. In order to estimate specific production rates (SPR; $\mu \mathrm{g}$ C produced $\mu \mathrm{g}$ body $\mathrm{C}^{-1} \mathrm{~d}^{-1}$ ), egg carbon estimates were made from the linear relationship between egg and female carbon found by Kiørboe \& Sabatini (1995).

At stations where more than 1 species was used, the estimations of EPR and SPR of the copepod community were calculated as the weighted average for the different experimental species taking into account their relative abundances; that is, the most abundant species had higher (proportional) representation in the final value.

\section{RESULTS}

The general patterns of temperature and chl a are shown in Fig. 2. Temperature reached its highest values in the tropical zone and decreased outside it. In contrast, chl a concentration followed the opposite trend. Higher maximum chl a concentrations were found at southern latitudes $\left(>35^{\circ} \mathrm{S}\right)$, and lower ones

Table 1. Representation of the distinct areas along the general transect defined according to the values (average $\pm \mathrm{SE}$ ) of temperature $\left({ }^{\circ} \mathrm{C}\right.$ ) chlorophyll a $\left(\mathrm{g} \mathrm{I}^{-1}\right)$ and copepod specific production $\left(\mathrm{d}^{-1}\right)$. PP\&SAT: Patagonia platform and South Atlantic temperate area; SASG: South Atlantic subtropical gyre; IE: intertropical area around the equator; NASG: North Atlantic subtropical gyre

\begin{tabular}{|lcccc|}
\hline & PP\&SAT & SASG & IE & NASG \\
\hline Latitude & $50^{\circ}-35^{\circ} \mathrm{S}$ & $35^{\circ}-10^{\circ} \mathrm{S}$ & $10^{\circ}-10^{\circ} \mathrm{N}$ & $10^{\circ}-25^{\circ} \mathrm{N}$ \\
Temperature & $14 \pm 0.5$ & $27 \pm 0.7$ & $28 \pm 0.3$ & $23 \pm 0.8$ \\
Chl a & $1.4 \pm 0.25$ & $0.3 \pm 0.04$ & $0.6 \pm 0.12$ & $0.6 \pm 0.09$ \\
Production & $0.03 \pm 0.008$ & $0.01 \pm 0.004$ & $0.08 \pm 0.022$ & $0.03 \pm 0.006$ \\
\hline
\end{tabular}

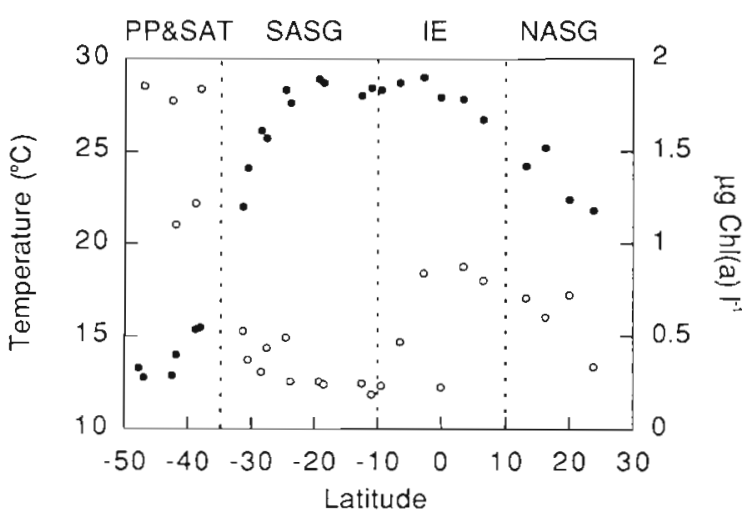

Fig. 2. Profiles of mixed layer temperature $(\bullet)$ and chl a (0) from the chlorophyll maximum along the experimental transect. The extension of the different latitudinal zones (PP\&SAT, SASG, IE and NASG) according to the values of $\mathrm{chl} a$ and temperature is also indicated (see text). Latitudes were designated as positive north of the equator and negative to the south

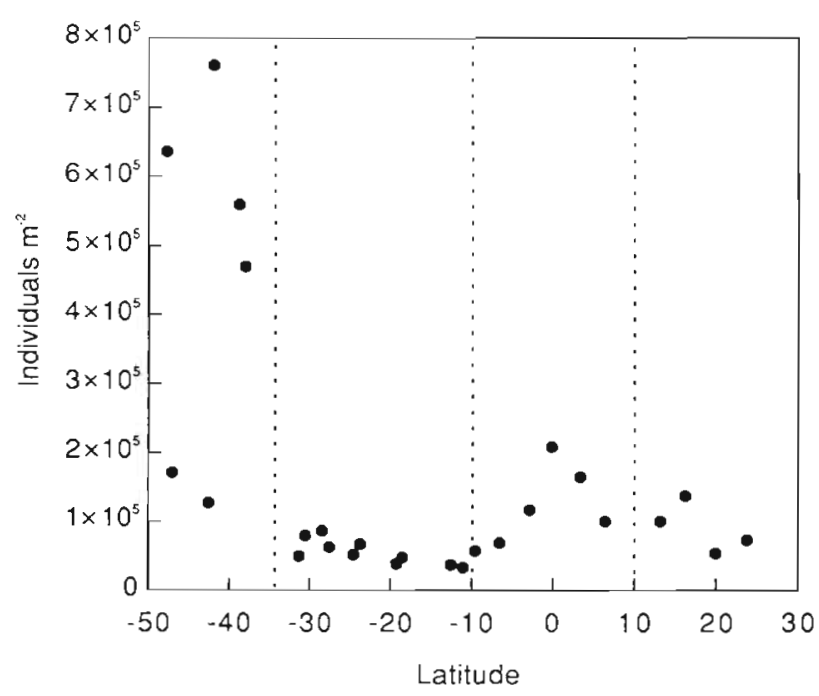

Fig. 3. Abundances of copepods (individuals $\mathrm{m}^{-2}$ ) along the transect

around the Tropics, with small increases in the vicinity of the equator (Fig. 2).

The patterns followed by water temperature and chl $a$ along the transect clearly characterized the different oceanographic areas sampled (Table 1), with high temperature and lowest values of chl a concentration at the SASG. There was negative correlation between the maximum chl a concentration and water temperature $(\mathrm{R}=0.72, p<0.001)$.

The latitudinal trend in copepod abundance (Fig. 3) was similar to that of maximum chl a concentration, with higher values at southern latitudes $\left(>35^{\circ} \mathrm{S}\right)$ and lower values 
Table 2. Relative abundances of the 3 most common genera at each station along the transect presented with a scale from 1 to 3 ,

1 being the most abundant. "Genera and stations for which the egg production rates were determined. Latitude values are designated as positive north of the equator and negative to the south

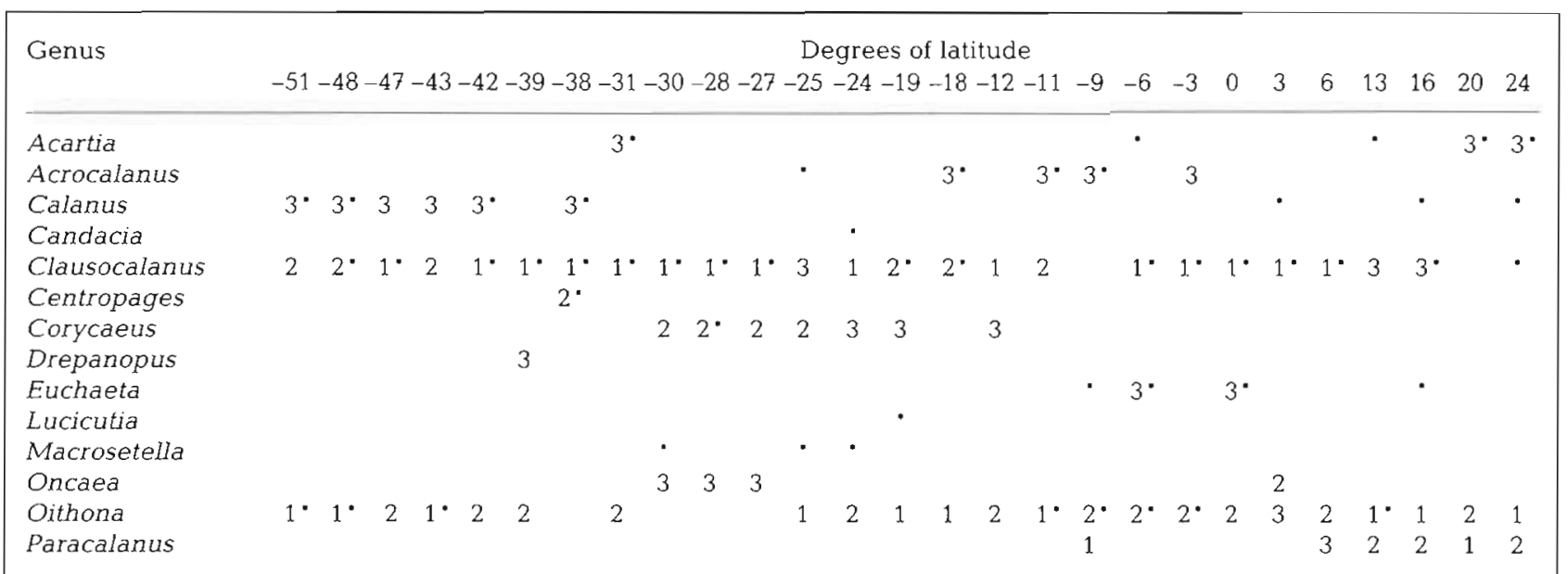
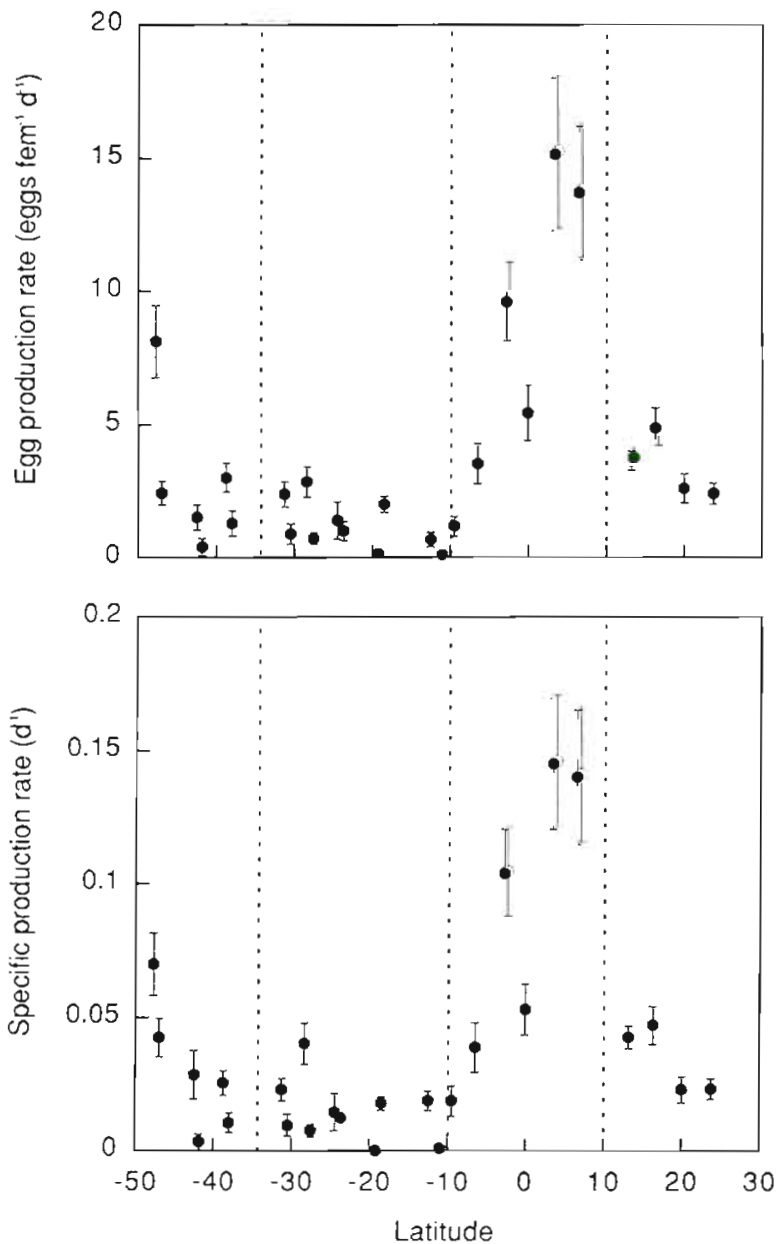

Fig. 4. Plot of the egg production rates (EPR and SPR) of the copepod community along the transect. Error bars represent 1 standard error in the SASG. In consequence, the correlation between copepod abundance and chl a was highly significant ( $R$ $=0.65, p<0.001$ ), while temperature was negatively correlated with the copepod abundance $(\mathrm{R}=0.63, \mathrm{p}<$ $0.001)$.

At most of the stations, the zooplankton community was dominated by egg-carrying copepods like Clausocalanus and Oithona spp. (Table 2). These 2 genera were the most abundant copepods at 55 and $37 \%$ (respectively) of the surveyed stations. Other important genera along the transect were Calanus spp. in the PP\&SAT, Corycaeus spp. in the SASG, and Paracalanus spp. in the NASG.

Egg production rate (EPR) and carbon specific production rate (SPR) along the transect are presented in Fig. 4. In general, production rates were very low (values close to zerol at south of $10^{\circ}$ and reached maximum values around the equator. Neither chl a nor temperature alone explained the variation in SPR (regressions not significant; $R=0.22$ and 0.17 , respectively), although the combination of these 2 factors in a multiple regression model explained up to $55 \%$ ( $p<$ $<0.001$ ) of the variance:

$\operatorname{SPR}\left(\mathrm{d}^{-1}\right)=-0.074 \mathrm{chl} a+0.008(T \times \mathrm{chl} a)-0.0172$

where $T=$ temperature (in ${ }^{\circ} \mathrm{C}$ ).

To allow for rate saturation at high resource concentrations, a more complex quadratic relationship for chl a was used (Hopcroft \& Roff 1998). The improved model explained $70 \%(p<0.001)$ of the variance:

$$
\begin{aligned}
\mathrm{SPR}= & -0.195 T-0.087 \mathrm{chl} a+0.009(T \times \mathrm{chl} a) \\
& -0.009 \mathrm{chl} a^{2}-0.0001\left(T \times \mathrm{chl} a^{2}\right)+1.277
\end{aligned}
$$

These equations were derived by first generating a global model including all possible interactions be- 
tween factors and later suppressing those that were not significant. Other models, including the size of the females and the integrated chl a for the water column, were also tested. However, the results showed that these 2 variables did not have a significant contribution in explaining the variance of SPR.

\section{DISCUSSION}

The results presented indicated that zooplankton abundance was related to the phytoplankton concentration. This is consistent with the idea that in a steady state system, the biomass of consumers is expected to be related to the availability of resources (Calbet et al. 1996). Thus, areas of the Atlantic Ocean with an elevated concentration of primary producers supported a higher biomass of consumers, independent of water temperature. It is to be expected, however, that temperature influences the rate of physiological processes. This is consistent with our results, where copepod production rates (as EPR and SPR) in the Atlantic Ocean can be explained by changes in both phytoplankton biomass and temperature.

With regard to copepod abundances, it is interesting to note the dominance along the transect of egg-sac carrying copepods like Oithona or Clausocalanus spp. (Table 2). Their occurrence, reinforced by observations in other studies (Chisholm \& Roff 1990, Peterson et al. 1991, Webber \& Roff 1995), suggests an adaptive advantage of this strategy versus broadcast spawners. Such an ecological success could have arisen if there was a reduction in the egg mortality in sac spawners as suggested by Kiørboe \& Sabatini (1995), or perhaps because the species possesses other advantages such as: relatively low metabolic demands (e.g. Clausocalanus, Mazzocchi \& Paffenhöfer 1998); a wide spectrum of acceptable food types (e.g. Oithona, Sabatini \& Kiorboe 1994); behavioral adaptations to avoid predation; a limited feeding specialization and relative longevity of the adults (e.g. Oithona, Paffenhöfer 1993).

Although copepod abundance may be well explained by maximum chl a concentrations alone in the Atlantic Ocean, the copepod EPR or SPR followed a more complex pattern, probably defined by a combination of temperature conditions and food concentrations. Thus, at low temperatures, even if the chl a concentrations were high, egg production rates were very low, as found in the Patagonia platform. In the SASG, where the low nutrient supply to the photic zone resulted in very low primary productivity (Agustí \& Duarte 1999, Planas et al. 1999), copepod production was lower, even though temperatures were higher. Further north, near the equator, the temperature was as high as in the subtropical gyre, where chl a concentrations were higher as a result of increased nutrient supply associated with equatorial upwelling (Planas et al. 1999). The increased water temperature and high primary production in the IE zone yielded the highest copepod production rates observed along the meridional transect. Lastly, in the southern area of the north subtropical gyre, the gradual reduction in temperature was apparently sufficient to significantly reduce copepod production rates. Hence, both temperature and food concentration appear to play important roles in the control of secondary production. Elevated temperatures cannot increase copepod production if food levels are insufficient, and at high food conditions, production can reach higher values following a temperature-dependent pattern. The optimal combination of these processes resulted in the highest copepod production located at the IE zone.

Although both temperature and food availability have been shown to affect secondary productivity of zooplankton (Uye 1981, Kleppel et al. 1996), the relative importance of both factors still remains controversial. Part of this discussion has been stimulated by the hypothesis of Huntley \& Lopez (1992) which proposes a minor role for food concentration in the control of secondary production. According to their results, when growth rate was measured using the physiological method, temperature explained $32 \%$ of the variance in growth rate estimates. However, if data on generation times and weights of eggs and adults were used in the calculations of growth rates, the variance explained by temperature alone was greater than $90 \%$. Although we cannot contrast our field measurements with their temperature-dependent model (no data on generation time was available), when compared with their physiological model, the variance of specific growth rates explained by temperature is as low as $2.5 \%$ (Fig. 5). In addition, if temperature was the main factor driving copepod growth rates, the SASG and the IE zone in the present study, which had similar temperature but food different resources, should display equivalent production rates and these should have been higher than those in other areas.

Much of the discrepancy between the predictions of Huntley \& Lopez (1992) and the present results could be due to the non-representative nature of the data used in the former analysis, which included few observations from tropical and subtropical open ocean ecosystems. Actually, most of the references presented for temperatures above $25^{\circ} \mathrm{C}$ corresponded to eutrophic bays, estuaries or coastal upwellings, which are not representative of the majority of tropical zones. The lack of data concerning warm and oligotrophic areas of the ocean reinforces the importance of oceanic tropical studies in order to increase the overall knowl- 


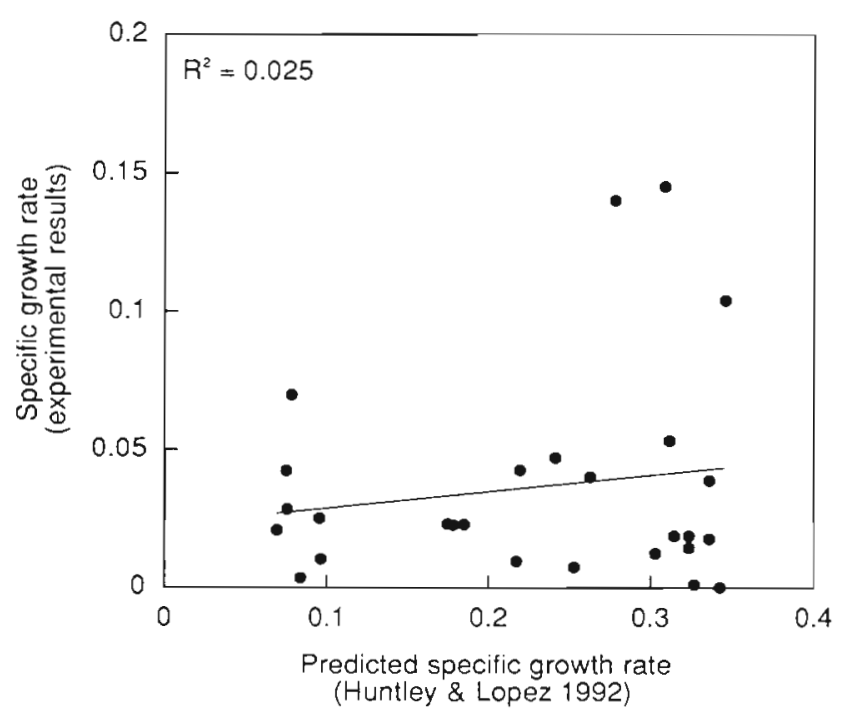

Fig. 5. Relationship between mean specific production rates $\left(\mathrm{d}^{-1}\right)$ obtained from the present experimental data and those predicted by the model presented by Huntley \& Lopez (1992)

edge on the functioning of marine ecosystems (Webber \& Roff 1995). We cannot forget, however, that the temperature-dependent model of Huntley \& Lopez (1992) considered only somatic growth. Later studies have suggested that the degree of food limitation in copepods varies with developmental stages (Hopcroft et al. 1998b). The present study only used egg production to measure growth. Hence, the different parameters estimated could also explain the variations found between models. However, a more recent model (Hirst \& Sheader 1997), proposed to predict copepod community (juveniles and adults) growth rates by using body weight and temperature, does not have better success in matching our field measurements $(\mathrm{R}=0.005)$. The data set used in the Hirst \& Sheader (1997) model also lacked values from oligotrophic ecosystems (e.g. subtropical and tropical open ocean areas), and presented only few measurements of adult growth rates. In addition, the insignificant role in our equations of copepod weight in explaining the variance of production rates may also help to understand the differences between models.

Another interesting point to discuss is the lack of fit of our model when integrated chlorophyll was used instead of chlorophyll from the maximum. This result may be explained by the close relationship existing between food and EPR and the use of water from the maximum of chlorophyll for the incubations. As some species respond very fast (less than $24 \mathrm{~h}$ ) in terms of egg production to changes in food availability, and since this response is a function of the temperature (Tester \& Turner 1990, Saiz et al. 1997), it is not surprising that these data were more closely related to
EPR and SPR than the values obtained by integrating the water column. This result not only reinforces the significance of food for modeling of the secondary production, but verifies the importance of the experimental conditions when estimating copepod production rates.

Although Eqs. (1) \& (2) are sufficient to demonstrate the combined effect of temperature and food availability on the control of copepod production rates (Fig. 6). they do not provide a global model for estimating copepod production. The elevated presence of sac spawners in the communities along the transect makes the production rates quite low and difficult to compare with those typical for free spawners. In addition, the model considers chlorophyll as the only parameter related to the nourishment of zooplankton. It is well known that copepods can feed efficiently on other food resources, such as heterotrophic flagellates or ciliates
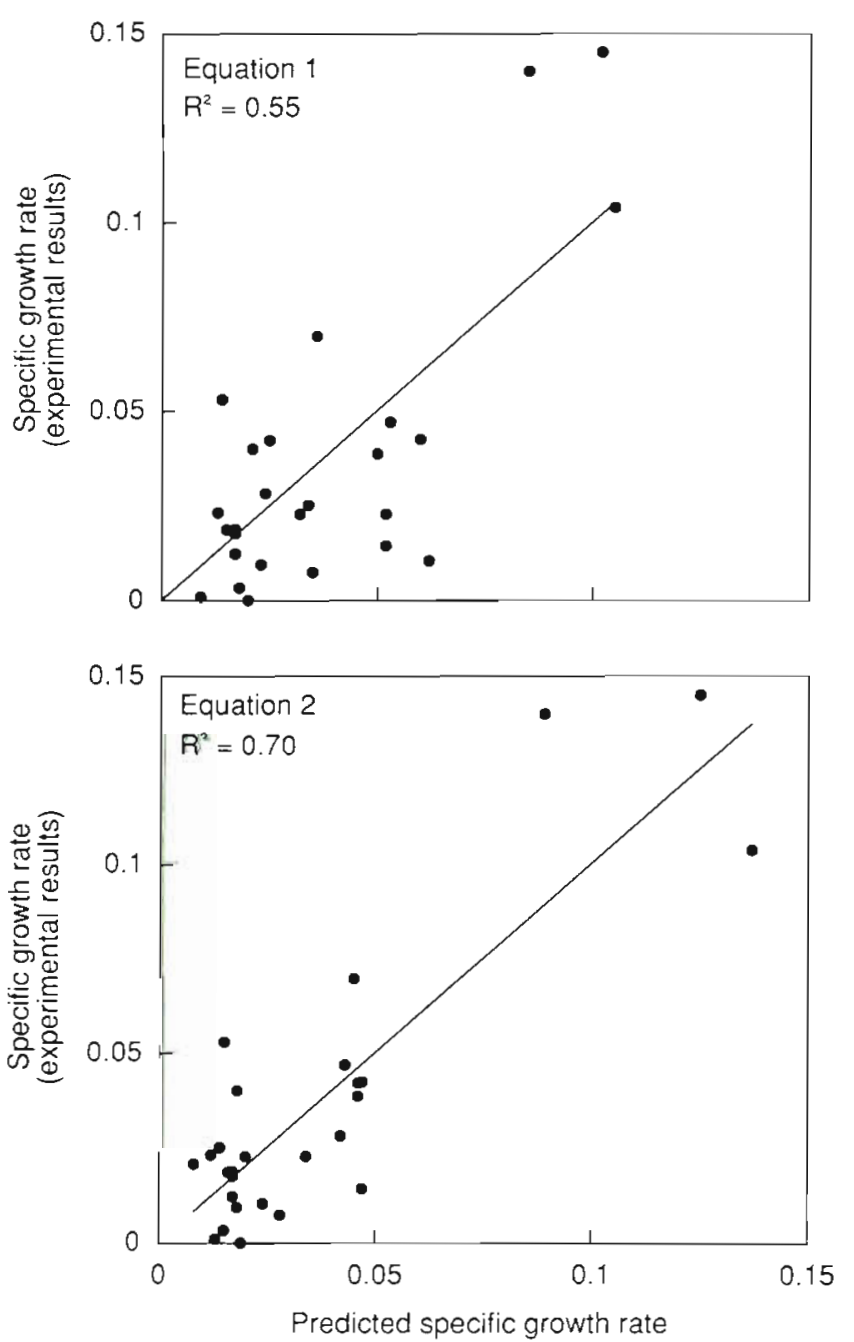

Fig. 6. Relationship between mean specific production rates $\left(\mathrm{d}^{-1}\right)$ obtained from the present experimental data and those estimated according to Eqs. 1 \& 2 (see text) 
(Jonsson \& Tiselius 1990, Fessenden \& Cowles 1994, Wickham 1995), and not all of the chlorophyll is in size fractions appropriate to be consumed (Conover 1982, Berggreen et al. 1988, Hansen et al. 1994). However, this variable (chl a) gives a good idea of the trophic condition of the ecosystem and has been widely used as a descriptive parameter for similar studies (Bathmann \& Liebezeit 1986, Van Rijswijk et al. 1989, Ishii 1990, Dam \& Peterson 1991, Calbet et al. 1996). Higher values of chlorophyll (even if too small for direct consumption by the copepods) usually mean more heterotrophs (flagellates and ciliates) which are a good source of nutrition for copepods (Jonsson \& Tiselius 1990, Dolan 1991, Fessenden \& Cowles 1994, Sabatini $\&$ Kiørboe 1994). Hence, the use of chl $a$ in the calculations is reasonable as an index of food concentration to compare general trends in the food availability of different areas.

Another assumption of the model is the generalization of the production response to changes in environmental conditions. It is well known that different species of copepods show variations in egg production rate when fed under similar food and temperature conditions (Dagg 1977, Jónasdóttir 1994, Calbet et al. 1996). These variations might be species specific or related to size (Hirst \& Sheader 1997), age (Parrish \& Wilson 1978), reproductive strategy (Kiørboe \& Sabatini 1995), etc. In other words, although models using relatively few independent variables are useful in giving general estimates of planktonic secondary production, they might be leading us away from a real understanding of marine ecosystems. In essence, the fewer the variables we include, the easier will be our calculations, but the less accurate will be our results.

Acknowledgements. This study was financially supported by grant AMB94-0739 from the Spanish Interministerial Commission of Science and Technology (CICYT) to S.A. and grants PN92-46651369 and EX96-46651369 from the Spanish Ministry of Universities and Research to A.C. I thank M. Landry, M. Alcaraz, E. Saiz and 4 anonymous reviewers for their advice and critical reading of the manuscript, J. Cebrián and M. P. Mura for their help on the collection of the experimental animals and chlorophyll data, respectively, and C. M. Duarte for CTD data. Fig. 1 was modified from an original by P. Gasol. Contribution 4787 from the School of Ocean and Earth Science and Technology, University of Hawaii at Manoa.

\section{LITERATURE CITED}

Agustí S, Duarte C (1999) Phytoplankton chlorophyll a distribution and water column stability in the Central Atlantic Ocean. Oceanol Acta 22:1-11

Bathmann U, Liebezeit G (1986) Chlorophyll in copepod faecal pellets: changes in pellet numbers and pigment content during a declining Baltic spring bloom. PSZN I: Mar Ecol 7:59-73
Berggreen U, Hansen B, Kiørboe T (1988) Food size spectra ingestion and growth of the copepod Acartia tonsa during development: implications for determination of copepod production. Mar Biol 99:341-352

Calbet A, Alcaraz M (1996) Effects of constant and fluctuating food supply on egg production rates of Acartia grani (Copepoda: Calanoida). Mar Ecol Prog Ser 140:33-39

Calbet A, Alcaraz M, Saiz E, Estrada M, Trepat I (1996) Planktonic herbivorous food webs in the Catalan Sea (NW Mediterranean): temporal variability and comparison of indices of phyto-zooplankton coupling based in state variables and rate processes. J Plankton Res 18(12): $2329-2347$

Chisholm LA, Roff JC (1990) Size-weight relationships and biomass of tropical neritic copepods off Kingston Jamaica. Mar Biol 106:71-77(A)

Conover RJ (1979) Secondary production as an ecological phenomenon. In: Spael S, Pierrot-Bults AC (eds) Zoogeography and diversity in plankton. Burge Scientific Publishers, Utrecht, p 50-86

Conover RJ (1982) Interactions between microzooplankton and other plankton organisms. Ann Inst Oceanogr 58 (Suppl):31-46

Conover RJ, Huntley ME (1980) General rules of grazing in pelagic ecosystems. In: Falkowski P (ed) Primary productivity in the sea. Plenum, New York, p 461-485

Corkett CJ, McLaren IA (1969) Egg production and oil storage by the copepod Pseudocalanus in the laboratory. J Exp Mar Biol Ecol 3:90-105

Dagg M (1977) Some effects of patchy food environments on copepods. Limnol Oceanogr 22:99-107

Dam HG, Peterson WT (1991) In situ feeding behavior of the copepod Temora longicornis: effects of seasonal changes in chlorophyll size fractions and female size. Mar Ecol Prog Ser 71:113-123

Davis CS, Alatalo P (1992) Effects of constant and intermittent food supply on life-history parameters in a marine copepod. Limnol Oceanogr 37:1618-1693

Dolan JR (1991) Microphagous ciliates in mesohaline Chesapeake Bay waters: estimates of growth rates and consumption by copepods. Mar Biol 111:303-309

Fessenden L, Cowles TJ (1994) Copepod predation on phagotrophic ciliates in Oregon coastal waters. Mar Ecol Prog Ser 107:103-111

Greze VN (1978) Production in animal populations. In: Kinne $O$ (ed) Marine ecology. A comprehensive integrated treatise on life in oceans and coastal waters, Vol IV, Dynamics Chap 3. J Wiley and Sons, New York, p 89-114

Hansen B, Bjornsen PK, Hansen PJ (1994) The size ratio between planktonic predators and their prey. Limnol Oceanogr 39(2):395-403

Harris RP, Paffenhöfer GA (1976) Feeding growth and reproduction of the marine planktonic copepod Temora longicornis Muller. J Mar Biol Assoc LK 56:675-690

Hirst AG, Sheader $M$ (1997) Are in situ weight-specific growth rates body-size independent in marine planktonic copepods? A re-analysis of the global syntheses and a new empirical model. Mar Ecol Prog Ser 154:155-165

Hopcroft RR, Roff JC (1998) Zooplankton growth rates: the influence of female size and resources on egg production of tropical marine copepods. Mar Biol 132(1):79-86

Hopcroft RR, Roff JC, Lombard D (1998a) Production of tropical copepods in Kingston Harbour, Jamaica: the importance of small species. Mar Biol 130:593-604

Hopcroft RR, Roff JC, Webber MK, Witt JDS (1998b) Zooplankton growth rates: the influence of size and resources in tropical marine copepodites. Mar Biol 132(1):67-77 
Huntley M, Boyd C (1984) Food-limited growth of marine zooplankton. Am Nat 124:455-478

Huntley ME, Lopez MDG (1992) Temperature dependent production of marine copepods: a global synthesis. Am Nat 140:201-242

Ishii $H$ (1990) In situ feeding rhythms of herbivorous copepods and the effect of starvation. Mar Biol 105:91-98

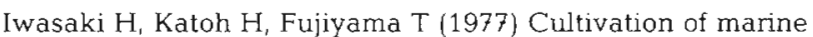
copepod, Acartia clausi Giesbrecht. I. Factors affecting the generation time and egg production. Bull Plankton Soc Jpn 24:55-61

Jónasdóttir SH (1994) Effects of food quality on the reproductive success of Acartia tonsa and Acartia hudsonica: laboratory observations. Mar Biol 121:67-81

Jonsson PR, Tiselius P (1990) Feeding behaviour prey detection and capture efficiency of the copepod Acartia tonsa feeding on planktonic ciliates. Mar Ecol Prog Ser 60:35-44

Kimmerer WJ (1984) Spatial and temporal variability in egg production rates of the calanoid copepod Acrocalanus inermis. Mar Biol 78(2):165-169

Kimmerer WJ, McKinnon AD (1987) Growth, mortality, and secondary production of the copepod Acartia tranteri in Westernport Bay, Australia. Limnol Oceanogr 32:14-28

Kiørboe T, Sabatini M (1995) Scaling of fecundity, growth and development in marine planktonic copepods. Mar Ecol Prog Ser 120:285-298

Kleppel GS, Davis CS, Carter K (1996) Temperature and copepod growth in the sea: a comment on the temperature-dependent model of Huntley and Lopez. Am Nat 148: $397-406$

Mazzocchi MG, Paffenhöfer GA (1998) First observations on the biology of Clausocalanus furcatus (Copepoda, Calanoida). J Plankton Res 20(2):331-342

McLaren IA (1963) Effects of temperature on growth of zooplankton and the adaptative value of vertical migration. J Fish Res Board Can 20:685-727

Paffenhöfer GA (1993) On the ecology of marine cyclopoid copepods (Crustacea, Copepoda). J Plankton Res 15:37-55

Parrish KK, Wilson DF (1978) Fecundity studies on Acartia tonsa (Copepoda: Calanoida) in standardized culture. Mar Biol 46:65-81

Parsons TR, Maita Y, Lalli CM (1984) A manual of chemical

Editorial responsibility: Otto Kinne (Editor), Oldendorf/Luhe, Germany and biological methods for seawater analysis. Pergamon, Oxford

Peterson WT, Tiselius P, Kiørboe T (1991) Copepod egg production moulting and growth rates and secondary production in the Skagerrak in August 1988. J Plankton Res 13: $131-154$

Planas D, Agustí S, Duarte CM, Granata TC, Merino M (1999) Nitrate uptake and diffussive nitrate supply in the Central Atlantic. Limnol Oceanogr 44:116-126

Sabatini M, Kiørboe T (1994) Egg production, growth and development of the cyclopoid copepod Oithona similis. J Plankton Res 16(10):1329-1351

Saiz E, Calbet A, Trepat I, Irigoien X, Alcaraz M (1997) Food availability as a potential source of bias on the egg production method for copepods. J Plankton Res 19(1):1-14

Tester PA, Turner JT (1990) How long does it take copepods to make eggs? J Exp Mar Biol Ecol 141:169-182

Uye S (1981) Fecundity studies of neritic calanoid copepods Acartia clausi Giesbrecht and A. steueri Smirnov: a simple empirical model of daily egg production. J Exp Mar Biol Ecol 50:255-271

Uye S (1982) Length-weight relationships of important zooplankton from the Inland Sea of Japan. J Oceanogr Soc Jpn 38:149-158

Van Rijswijk P, Bakker C, Vink M (1989) Daily fecundity of Temora longicornis (Copepoda: Calanoida) in the Oosterschelde estuary (SW Netherlands). Neth J Sea Res 23(3): 293-303

Vidal J (1980) Physioecology of zooplankton. I. Effects of phytoplankton concentration, temperature and body size on the growth rate of Calanus pacificus and $P_{\text {seudo- }}$ calanus sp. Mar Biol 56:111-134

Webber MK, Roff JC (1995) Annual biomass and production of the oceanic copepod community off Discovery Bay, Jamaica. Mar Biol 123:481-495

Wickham SA (1995) Trophic relations between cyclopoid copepods and ciliated protists: complex interactions link the microbial and classic food webs. Limnol Oceanogr 40(6):1173-1181

Zurlini G, Ferrari I, Nassogne A (1978) Reproduction and growth of Euterpina acutifrons (Copepoda: Harpacticoida) under experimental conditions. Mar Biol 46:59-64

Submitted: November 9, 1998; Accepted: January 7, 1999

Proofs received from author(s): April 30, 1999 